\title{
QEE: VR GAME THAT AIMS TO TEST AND ENHANCE THE PLAYER'S KNOWLEDGE OF TAJWEED
}

\author{
Haya AlKhateeb, Zainab AlSamel, Joud AlBarazi and Evi Indriasari Mansor \\ Department of Computer Science, College of Computer \& Information Sciences, Prince Sultan University, \\ Riyadh, Saudi Arabia
}

\begin{abstract}
This paper aims to provide an effective computer game which, in addition to entertaining players, helps improving their knowledge of Tajweed. Tajweed is an Islamic science that studies the correct recitation of the Qur'an words and letters. It has been proven that learning at an early age gives more reliable and long-lasting knowledge. In addition, teenagers are more capable of controlling their pronunciation and modifying them. For these reasons, Qee game targets the ages between 13 and 18. As teenagers nowadays are exposed to a variety of game technologies, which raised their expectations and satisfaction level, a 3D VR game was introduced as an attractive modern solution. A prototype of two levels was developed and tested by 20 participants. The testing session resulted in a successful outcome with some suggestions for future modifications.
\end{abstract}

\section{KEYWORDS}

Tajweed, Gamification, Virtual Reality, Education

\section{INTRODUCTION}

Teenagers nowadays are spending too much time on their devices, most of the time enjoying games that have no benefit other than entertaining. Therefore, developing an attractive game would be an ideal and effective way to help them make a better use of their time. This research aims to provide this informative and enjoyable game. The content of the game was chosen to be related to the knowledge of Tajweed (the rules of pronunciation when reading the Qur'an). The reason for that is that the teachers of Tajweed are noticed to be facing difficulties in attracting the students and helping them to develop their Tajweed skills. In addition, perceiving information in such an enjoyable way helps retaining and strengthening them. Looking through the applications that are concerned with the knowledge of Tajweed, all are found to be purely educational which is not really the interest of the teenagers. Others may include some gaming, but they are usually of a low quality and don't provide the user with the desired level of interactivity. In general, they are not as attractive as other popular games are. This reduces their popularity among youths. Therefore, the new technology of VR was an interesting idea to apply as it is one of the most appealing and trendy devices used by today's generation. Ultimately, Qee - a Virtual Reality (VR) in 3D environment game is proposed to serve as a solution. Qee is an Arabic word that means the imperative verb of protection. This name conveys the main task in the game which requires the user to protect himself from the devil. This is done through achieving several tasks in each level (explained in detail throughout the paper). The HTC Vive set is used as the interaction device which allows the player to view the game via a special headset and two hand controllers to interact with the game.

\section{RELATED WORK}

The topic of this paper can be viewed as a combination of two research areas: e-learning and gaming. The e-learning systems have caught the interests of the researchers many years ago and there are quite a lot of papers considering e-learning for teaching Tajweed. However, very few of them address this issue by 
providing a solution in the gaming field, which is in most cases not as entertaining as the proposed game in this paper. Several papers worked on speech recognition to correct recitation. Many of them relied on Mel-Frequency Cepstral Coefficient (MFCC) algorithm for feature extraction and Hidden Markov Models (HMM) for classification. Ahsiah et al. (2013) suggested an e-learning technique that applies speech recognition mechanisms to figure out the mistakes made by the students through comparing them with a database of recitations recorded for experienced teachers. This approach applies MFCC and HMM algorithms. Another study that uses these two algorithms was done by Yousfi et al. (2017). They used natural language processing to extract and correct a specific rule of tajweed named Iqlab. In this paper ASR speech recognition system is used to identify the spoken versus. The proposed system is capable of pointing out the mismatch in this rule with an accuracy of $70 \%$ obtained for words that were included in the training database of famous reciters and $40 \%$ for new words that classifiers was not trained on.

Another educational tool is provided by Ibrahim et al. (2013) and it also uses MFCC and HMM. This system is a Quranic verse recitation recognition system with a function that checks for the rules of tajweed. It was tested on Surat AlFatiha. The resulted recognition rate is $91.95 \%$ (ayates) and $86.41 \%$ (phonemes). One more purely educational solution is proposed by Marlina et al. (2018). This study is more focused on a specific and basic rule of tajweed which is called Makhraj. Makhraj is the rule that specifies how each letter is correctly pronounced by identifying the speech organ that produces it. Kapi et al. (2017) developed an e-learning application that focuses on teaching the surah of Yassin. A combination of audio, video and animation was implemented in the application. The application focuses on the mistakes of the previous students who have taken the course in the traditional way. By testing the application on 51 students, it was found that the application helps in reducing the number of mistakes made by the students, the instructional time and supports self-studying. A new mechanism that is focused on practically improving the recitation is proposed by Altalmas et al. (2017). This technique uses lips tracking identification methods to extract the correct way of pronouncing the letters from video records for professional reciters. Then the extracted lips movements and final shapes are used to check the recitation of novice readers and figure out their mistakes. It also gives suggestions for improving the recitation.

Furthermore, a study done by Alfaries et al. (2013) applies natural language processing techniques in order to extract the tajweed rules from the Qur'an text and annotate them. In this study, GATE environment was used to develop an application that processes and annotates the text. The followed approach uses two tokenizers (word and letter tokenize) then applies Java Annotation Patterns Engine (JAPE) for annotating the rules. Precision and recall metrics were used to evaluate the application with a $100 \%$ result for both metrics. Learning tajweed is also supported through the proposed online portal for all sciences related to Qur'an. This portal is suggested Adhoni et al. (2013) and it is made accessible through different devices. A friendly mobile app is also developed. Ragheb and Mahmoud (2013) have studied the effectiveness of one of the major computer softwares in this area which is The Hafs Tajweed Teacher Software. The software was tested on 200 users in four countries. The experiment proved the important role of Hafs software in accelerating the learning process especially for beginners.

Moreover, researchers have also used deep learning techniques to enhance the solutions provided for teaching tajweed. Al-Ayyoub et al. (2018) proposed an approach that uses Convolutional Deep Belief Network (CDBN) which improved the accuracy of the classification to 97.7\%. Support Vector Machine classifier was used to classify the features extracted from thousands of records for reciters from both genders. Moving to the work that integrates some entertaining methods, Tajweed Race Online Game Via Facebook Platform introduced an enthusiastic multiplayer game prototype for children in age range of seven to twelve years old. Its aim is to enrich and assess children's knowledge of Tajweed. It contains highly attractive factors. Children can communicate and at the same time play and compete with their friends. The winner is identified using a specific formula that calculates time, speed and player's correct answers. All these factors energize the game players to participate and consequently learn more about Tajweed rules. An interactive game was proposed by Nurtihah et al. (2018) but has not yet been implemented. This game also includes the use of AR. The approach was designed and developed using an instructional design model (ADDIE) with five basic stages: Analysis, Design, Development, Implementation and Evaluation. Learners can scan a marker in an AR book which leads them to different challenges, videos, animations that explain and examine the learners' knowledge.

A suggested approach by Basuhail (2013) takes into consideration instructors who don't have good IT skills. In his paper, Basuhail, provides a workable model that is simple and straightforward for implementing learning objects. The approach circulates through several steps: planning, interface, visuals, multimedia, 
texting, formatting, animation, integration and testing. Based on a chosen topic, the instructor can add the suitable buttons, animations, windows and play with many other options to produce an effective teaching object that can be used separately or integrated in an e-learning environment. Most importantly, it satisfies each student's preferable style of learning. For example, the student can listen to a sound of specific letter pronunciation, read its description or see a picture that visualizes the actual positioning of the internal organs with the pronunciation of that letter. As noticed, the uniqueness of this paper comes from the high level of attractiveness and entertainment accompanied by the educational value. The following sections are organized as follows: the first section explains the methodology in detail covering the design, development and testing procedures. The next section includes the results and discussion. Finally, the conclusion section sums up the paper.

\section{MATERIALS AND METHODS}

The immersive experience in this game is driven to the player using HTC Vive device (Figure 1). It is a wearable device that is mainly composed of a headset, two controllers and two base stations. It requires very powerful computers with at least $4 \mathrm{~GB}$ of memory and processors of high performance [Intel ${ }^{\circledR}$ Core ${ }^{\mathrm{TM}}$ i5-4590 or AMD FX ${ }^{\mathrm{TM}}$ 8350, equivalent or better] (VIVETM|VIVE Virtual Reality System, n.d.). The device is not cheap, but is still affordable. Its downsides mainly include the technical issues that the users face while setting up the device and the time consumed to get it ready. Regarding the software, two main platforms were used: Unity (mainly for the game development) and Blender (for the 3D objects and environment design).

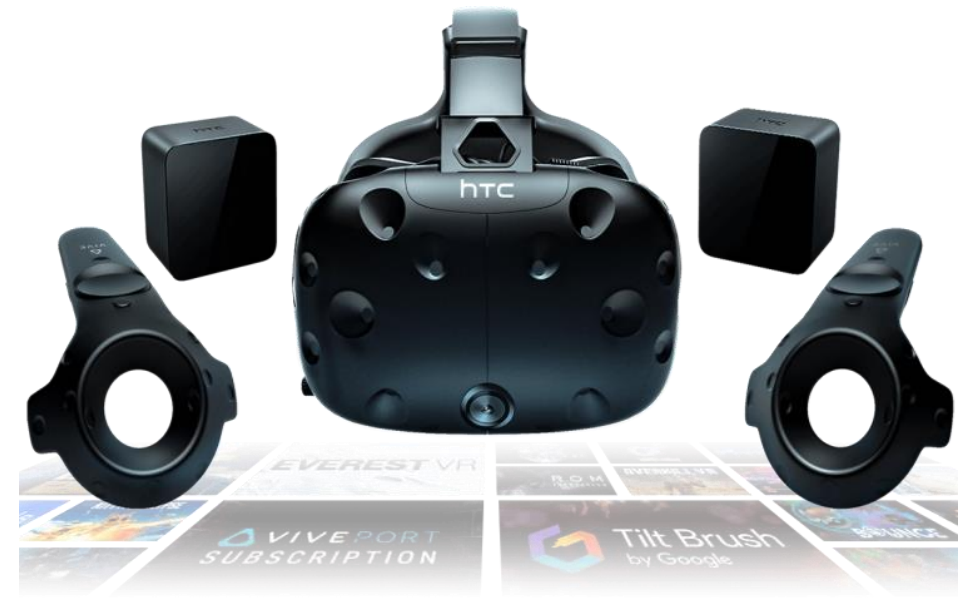

Figure 1. HTC Vive device

\section{DESIGN}

The first step was conducting a brainstorming session to get the teenagers' preferences (ages 13-18) and consider them in the game design and development. The participants' requirements were mostly focused on a good graphic design quality, immersive music and sound effects and the use of modern technologies such as AR and VR. Based on these results a basic design was proposed. The basic task of the game is for the player to protect himself from the devil (Figure 2a). To do so, the player has to collect an object by the end of each level. This object is symbolised in the Qee game logo (Figure 2b). The only way to be able to collect this object is to succeed in each level's challenge. Once all levels are passed successfully, the devil dies and the player gets his freedom. 
(a)

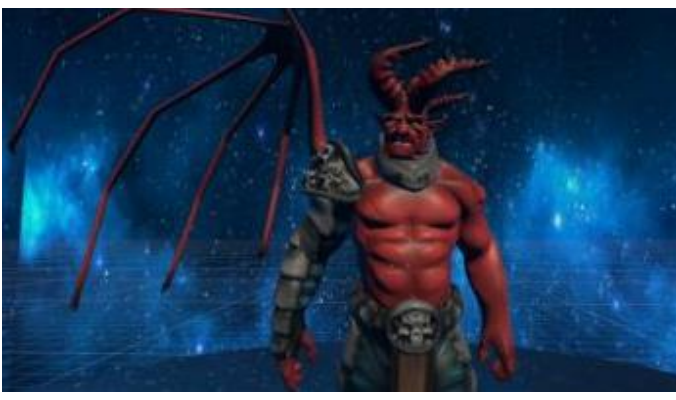

(b)

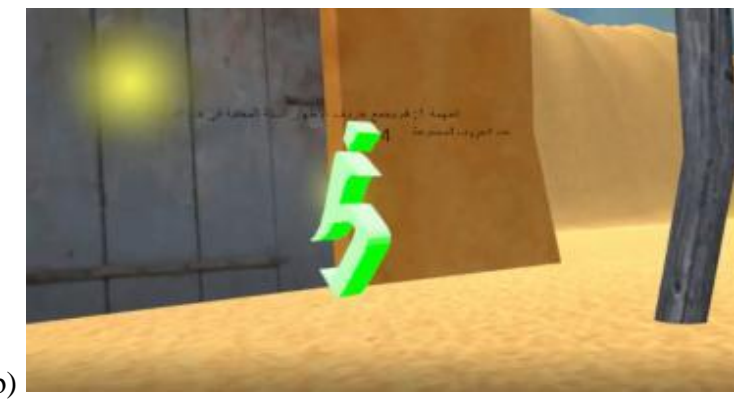

Figure 2. (a) Devil character; (b) Collectable object - the Qee game logo

The details of each level are as follows:

\subsection{Level 1}

This level takes place in a desert setting with trees scattered here and there (Figure 3a). In this level there are six correct collectables (Figure 3b) which are Arabic letters that constitute together the correct answer of the following question: What are the correct letters of Izhar (a very well known rule in Tajweed)? Find them scattered in this level. This question is displayed to the user on the screen. The level contains a maze that leads to the object required by the devil. The maze gate is locked until the player gets all the collectables. Once he does so, the player can enter the maze, find the object and win the level.

(a)

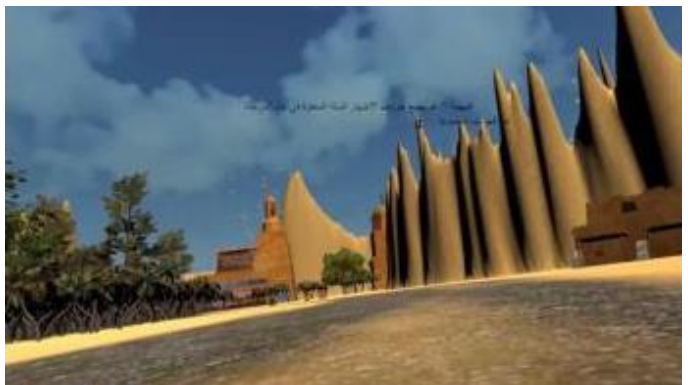

Figure 3. (a) Level 1- Desert setting; (b) Collectable objects

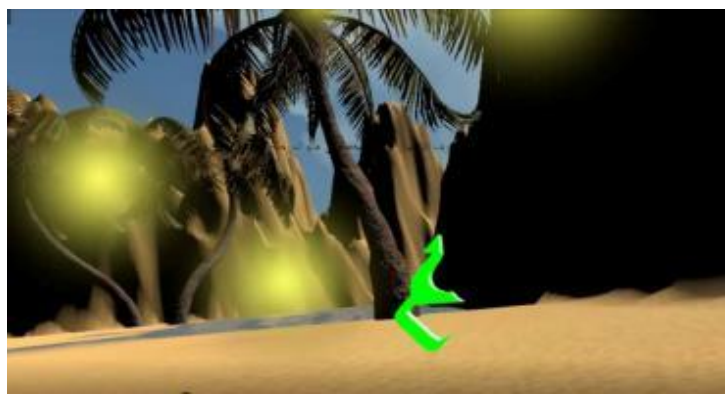

\subsection{Level 2}

Level 2 takes place in an underground cave setting. This level has a scary theme. The player goes through several paths. There are two questions each with three options. The possible answers are Arabic letters that can be picked up using the controllers. The user has to pick the right letter, or his score will decrease. Once the player answers the two questions, he will be able to collect the object which will be hidden somewhere in the level's environment (Figure $4 \mathrm{a} \& \mathrm{~b}$ ). By collecting this object, the player wins this level and the game ends with a scene showing the devil dying.

(a)

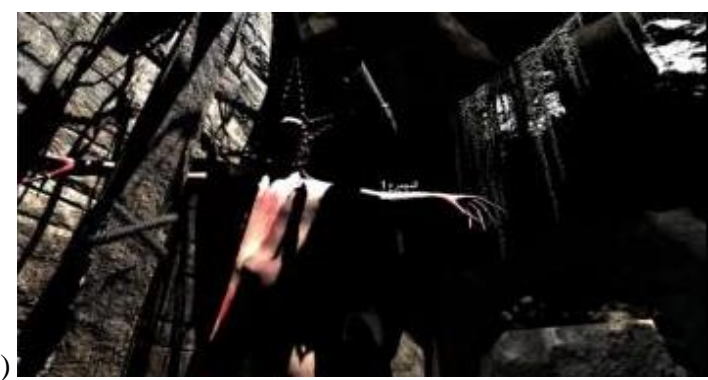

(b)

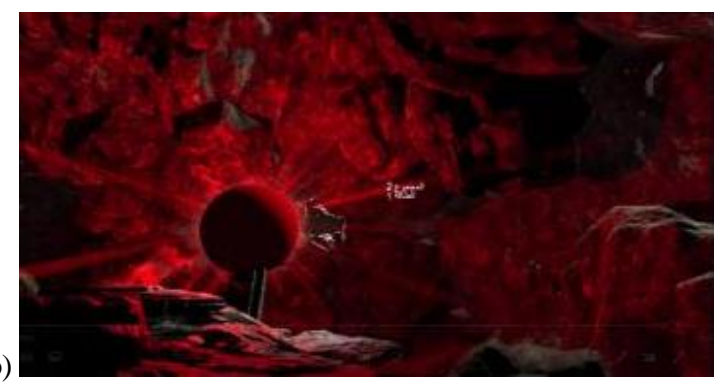

Figure 4. a \& b: Level 2 - Cave setting 


\section{DEVELOPMENT}

This game was developed using Unity software accompanied by Visual Studio for the codes. Blender was used for creating 3D models. The game was mainly developed in two stages: building the environment, and creating the required codes according to the player's movement and tasks.

Unity allows the user to come up with a variety of very creative environments. Raising terrains, adding textures, creating particle systems and many other techniques are some of the very powerful design options provided by Unity. Some assets were imported from Unity Asset Store as well (Unity Asset Store - The Best Assets for Game Making, n.d.).

Regarding the coding part, the following functionalities were implemented: walking, collecting by colliding with an object, answering through the laser pointer and grapping. Some important settings needed to be modified for the Vive to work properly such as freezing rotation or checking the gravity option to let the objects behave as if they are in the real world.

\section{USER STUDY}

The testing was conducted to evaluate the efficiency of the game and get user feedback for improvement suggestions. Two questions were proposed:

- Is the game entertaining enough to attract teenagers?

- Is it helpful in improving the player's knowledge of Tajweed?

To answer these questions the testers' interactions were carefully monitored during the testing session. In addition, a post-testing survey was given to the players to get their neutral opinion and suggestions.

\subsection{Setting}

Since the target audience of this study is teenagers, the testing was decided to be done in Alfahd private school, Riyadh, KSA, that has students from grade seven to twelve in one campus. The VR device was set up in a room with enough space for the players to move freely while playing (Figure 5). Since some people face motion sickness while using virtual reality technology, a chair was provided if this case was encountered. The laptop, the information sheet, consent form and all the required materials were arranged on a desk beside the device set up. Mobile phones were used for the online survey.

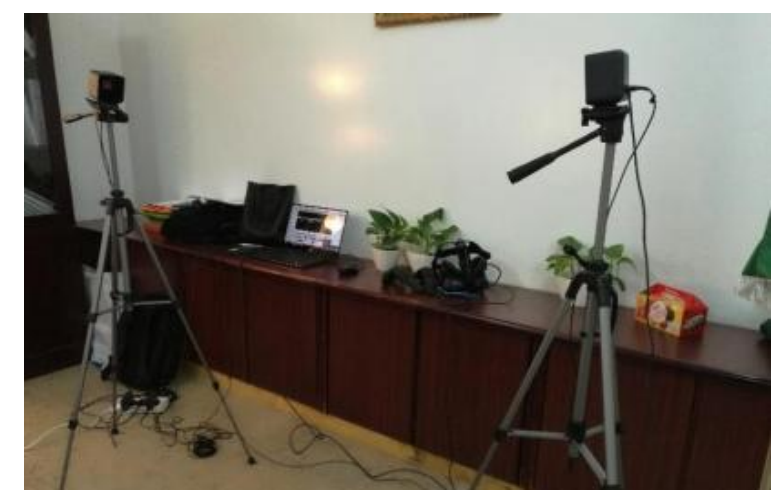

Figure 5. Testing setting

\subsection{Participants}

The game was evaluated with 20 female participants of ages between 13 and 18, with 59\% and $41 \%$ percentages for middle and high school respectively. Only female students were recruited in this study due to the gender segregation system at school in Saudi Arabia. Therefore, since all the team members of this research are female, the research team had no access to the male section at the period of the user study. The 
sample was chosen randomly to cover a diversity of technical backgrounds. A pre-testing survey was conducted to collect demographic information about the players and their backgrounds. The survey shows that $58 \%$ of the participants have a previous experience with a VR device. The percentage of using computer games varied between daily, weekly and monthly, with (once a week) option being the most significant (Figure 6). In terms of the tajweed knowledge background, only $15 \%$ of them did not have any previous experience in learning Tajweed. Most of those who have learned tajweed previously were taught by a teacher. Some of them used other methods such as books, mobile app. Most of the players were familiar with at least two of the tajweed lessons covered by the game challenges.
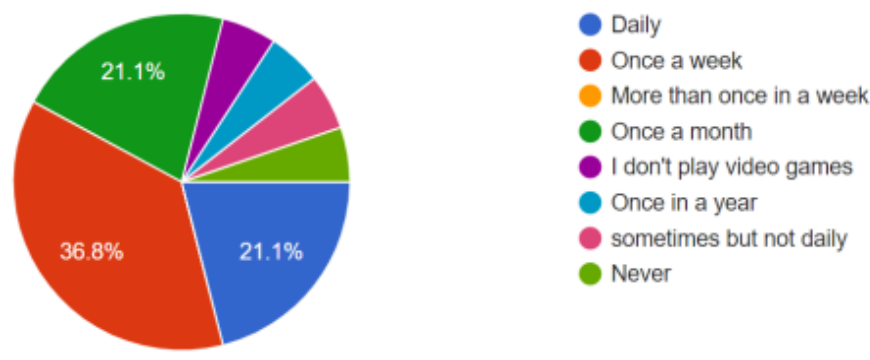

Figure 6. Answering result to question: How often do you play computer games?

\subsection{Procedure}

The testing session lasted for about 15-20 minutes for each player. After introducing the project and the team to the testers, they went one by one through the following steps:

(a) Reading information sheet and signing the consent form

(b) Completing the pre-testing survey

(c) Playing the game

(d) Completing the post-testing survey

All participants were notified about the probability of getting dizzy and were requested to note it immediately if it happened. After that, the participant was given the controllers and helped to wear the headset and adjust its size. Then the game was started. Some players managed to win the first level and move to the second one while others only tested the first level.

\section{RESULTS}

The results were obtained by analyzing the post-testing survey answers and monitoring the players' reactions and attitudes while playing. The survey questions covered three areas: playing experience, game interface and game content. All players tried out level 1 whereas only $42 \%$ of them tested level 2.

Based on the players' answers in the playing experience section, $94.7 \%$ of the players strongly enjoyed playing the game (Figure 7), 52\% of them found it challenging and $100 \%$ showed their interest to try it again. When asked to measure the difficulty of each level, most of the testers rated level one as easy, considering its collecting method (i.e. collect by colliding) the most comfortable one. The reason for that is that the player's attention is focused only on walking by touching the controller's forward button. On the other hand, answering with the controller (laser and picking) requires more effort from the player to manage using both controllers, one for walking and the other for answering. Therefore, most players who tried level 2 rated it as medium or hard.

To evaluate the game interface, questions were asked about the creativity and quality of the graphics. As shown in Figure 8,73.7\% of the participants strongly enjoyed the design of the environment. However, it was a common note among testers that the clarity of the displayed texts needs to be increased.

For the last examined area, the game's content, all participants replied positively to the question that asks about their familiarity of Tajweed. However, not all of them managed to answer all the questions. This ensures the role of the game in refreshing and enhancing the players' knowledge of Tajweed. Furthermore, $84.2 \%$ of the participants agreed that the game helps supporting their knowledge (Figure 9). 


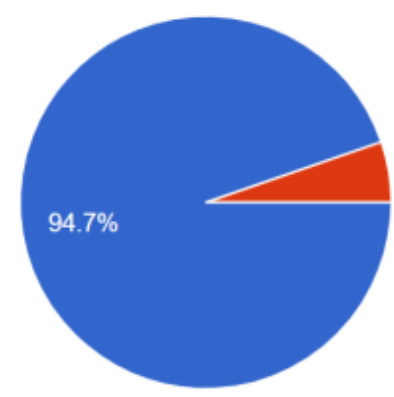

Strongly enjoyed it

Slightly enjoyed

Didn't enjoy it

Figure 7. Answering result to question: To what extent did you enjoy playing the game, rather than something you were just doing?

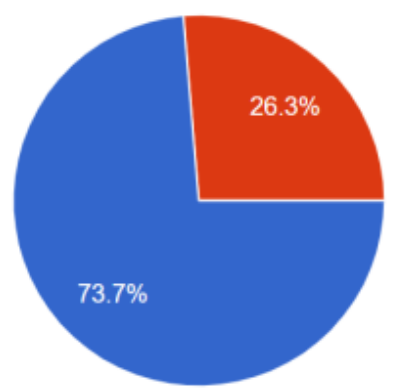

Strongly enjoyed it

Slightly enjoyed

Didn't enjoy it

Figure 8. Answering result to question: To what extent you enjoy the graphics and the imagery?

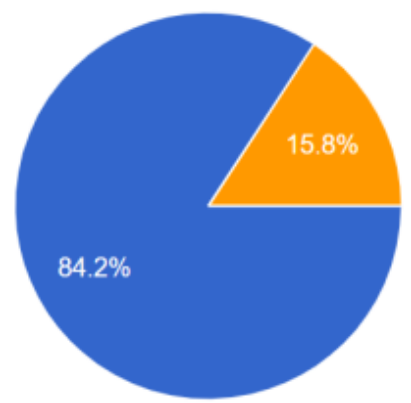
Yes
To some extent

Figure 9. Answering result to question: Did you find the game helpful to support your knowledge of Tajweed?

\section{DISCUSSION}

Going back to the main proposed questions: "Is the game entertaining enough to attract teenagers?" and "Is it helpful in improving the player's knowledge of tajweed?" and taking the players' feedback into account, many outcomes can be derived. First of all, the testing has proved that the game has an appealing design, and a novel and unique playing technique that catches the player's attention. The immersive experience provided by the game comes from the combination of the realistic environment (Figure 2) with some fantastic characters (Figure 2a) and props (Figure $3 \& 4$ ). Secondly, the questions added a sense of challenge and aided in reviewing some Tajweed information, which fulfills the game's purpose.

Beside these remarkable findings, some modifications were extracted from the players' reactions and recommendations. From the user experience perspective, the instructions of using the controllers have to be stated more clearly, especially for those who have not tried a VR device previously. In addition, the font's size and resolution must be increased. Talking about the development aspect, level two has some gaps where the player falls down unexpectedly. These comments will be taken into consideration in future improvements. 


\section{CONCLUSION}

Proceeding from the teenagers' attitude of spending too much time playing computer games and the importance of learning in this age, the idea of developing an entertaining game that at the same time participate in educating an important science was introduced. Noticing teenagers' need for a variety of educational resources and ways in Tajweed science resulted in choosing it for the game content. Tajweed is a science that teaches the correct pronunciation of letters and words in reciting Qur'an. A VR 3D design was chosen for the game to be attracted and satisfying enough for today's teenagers. The testers showed their excitement and enthusiasm towards the game's environment and challenge. Our future work will focus on expanding this game to have more levels and challenges. Furthermore, we plan to test the game with teenage male participants.

\section{ACKNOWLEDGEMENT}

We would also like to thank AlFahad School for giving us permission to do the testing in their school. Lastly, we would like to express our gratitude to our families for their permanent support. Indeed, none of this would be possible without them. This work was supported by the Human Computer Interaction Research Group; Prince Sultan University; Riyadh; Saudi Arabia [RG-CCIS-2017-06-01].

\section{REFERENCES}

A. Ragheb and A. Mahmoud. 2013. The Role of e-Learning Software in Teaching Quran Recitation. IEEEXplore.

A. Alfaries, M. Albahlal, M. Almazrua and A. Almazrua. 2013. A Rule Based Annotation system to extract Tajweed Rules from Quran. IEEXplore.

Altalmas, T.M., Jamil, M.A., S. Ahmad, W. Sediono, Salami, M.J.E., Hassan, S.S. and Embong, A.H. 2017. Lips tracking identification of a correct pronunciation of quranic alphabets for Tajweed teaching and learning. IIUM Engineering Journal, Vol. 18, pp. 1-15.

Adhoni, Z.A., H. AlHamad, Siddiqi, A.A. and L. El Mortaji. 2013 Towards a Comprehensive Online Portal and Mobile Friendly Qur'an Application. IEEXplore.

Basuhail, A.A. 2013. A Model for Implementing E-Teaching Objects for the Holy Quran and Related Sciences Using Animations. IEEEXplore.

Beck, K. and Ralph, J., 1994. Patterns Generates Architectures. Proceedings of European Conference of Object-Oriented Programming. Bologna, Italy, pp. 139-149.

B. Yousfi, Zeki, A.M and A. Haji. 2017. Isolated Iqlab checking rules based on speech recognition system. IEEEXplore.

Ibrahim, N.J., Idris, M.Y.I., Z. Razak and Abdul Rahman, N.N. 2013. Automated Tajweed Checking Rules Engine for Quranic Learning. Multicultural Education \& Technology.

I. Ahsiah, Noor, N.M. and Idris, M.Y.I. 2013. Tajweed Checking System to Support Recitation. IEEEXplore.

Kapi, A.Y., N. Osman, Ramli, R.Z. and Taib, J.M. 2017. Multimedia Education Tools for Effective Teaching and Learning. Telecommunication, Electronic and Computer Engineering, Vol. 9, pp. 2-8.

L. Marlina, C. Wardoyo, Sanjaya, W.S.M., D. Anggraeni, Dewi, S.F., A. Roziqin and S. Maryanti. 2018. Makhraj recognition of Hijaiyah letter for children based on Mel-Frequency Cepstrum Coefficients (MFCC) and Support Vector Machines (SVM) method. IEEEXplore.

M. Al-Ayyoub, Damer, N.A.M. and I. Hmeidi. 2018. Using Deep Learning for Automatically Determining Correct Application of Basic Quranic Recitation Rules. The International Arab Journal for Information Technology, Vol. 15.

Nurtihah, M.N., Yussof, R.L., Yusoff, F.H. and M. Ismail. 2018. Gamification and Augmented Reality Utilization for Islamic Content Learning: The Design and Development of Tajweed Learning. User Science and Engineering.

Unity Asset Store - The Best Assets for Game Making. (n.d.). Retrieved from https://assetstore.unity.com/

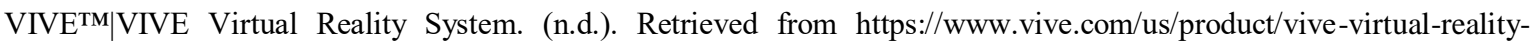
system/ 